This item was submitted to Loughborough's Research Repository by the author.

Items in Figshare are protected by copyright, with all rights reserved, unless otherwise indicated.

\title{
Fiber laser induced surface modification/manipulation of an ultrasonically consolidated metal matrix
}

PLEASE CITE THE PUBLISHED VERSION

http://dx.doi.org/10.1016/j.jmatprotec.2013.04.008

PUBLISHER

(c) Elsevier

VERSION

AM (Accepted Manuscript)

\section{PUBLISHER STATEMENT}

This work is made available according to the conditions of the Creative Commons Attribution-NonCommercialNoDerivatives 4.0 International (CC BY-NC-ND 4.0) licence. Full details of this licence are available at: https://creativecommons.org/licenses/by-nc-nd/4.0/

\section{LICENCE}

CC BY-NC-ND 4.0

\section{REPOSITORY RECORD}

Masurtschak, Simona, Ross J. Friel, Arnold Gillner, J. Ryll, and Russell A. Harris. 2019. "Fiber Laser Induced Surface Modification/manipulation of an Ultrasonically Consolidated Metal Matrix". figshare.

https://hdl.handle.net/2134/16880. 


\section{Fiber Laser Induced Surface Modification/Manipulation of an Ultrasonically Consolidated Metal Matrix}

S. Masurtschak ${ }^{a^{*}}$, R. J. Friel ${ }^{a}$, A. Gillner ${ }^{b}, J^{2}$ Ryll ${ }^{b}$, R.A. Harris ${ }^{a}$

${ }^{a}$ Wolfson School of Mechanical and Manufacturing Engineering, Loughborough University, Loughborough, Leicestershire, LE11 3TU, UK

${ }^{\mathrm{b}}$ Fraunhofer Institute for Laser Technology, Steinbachstrasse 15, 52074 Aachen, Germany

\section{Abstract}

Ultrasonic Consolidation (UC) is a manufacturing technique based on the ultrasonic joining of a sequence of metal foils. It has been shown to be a suitable method for fibre embedment into metal matrices. However, integration of high volume fractions of fibres requires a method for accurate positioning and secure placement to maintain fibre layouts within the matrices. This paper investigates the use of a fiber laser for micro channel creation in UC samples to allow such fibre layout patterns. A secondary goal, to possibly reduce plastic flow requirements in future embedding processes, is addressed by manipulating the melt generated by the laser to form a shoulder on either side of the channel. The authors studied the influence of laser power, traverse speed and assist gas pressure on the channel formation in aluminium alloy UC samples. It was found that multiple laser passes allowed accurate melt distribution and channel geometry in the micrometre range. An assist gas aided the manipulation of the melted material. 
Keywords: Ultrasonic Consolidation, Fiber Laser, Melt ejection, Aluminium, Additive Manufacturing, Assist Gas

\section{Introduction}

The primary mechanism behind channel production with a laser is that the heat of the laser is used to generate channels by melting or vaporisation of the material. Especially in the case of melting the material, an assist gas is needed to expel the molten material out of the groove. As opposed to laser cutting, channel production via laser-use can be more considered as a 3D process taking into account the height, width and depth of the channel.

Within the range of laser machining processes the production of channels with the aid of an assist gas has been established as laser grooving (Chryssolouris et al., 1988). Chryssolouris et al. (1988) found that a linear relationship between the groove width and power density exists. A theoretical model for the depth prediction was introduced by Choi and Chryssolouris (1995) in which it was predicted that an increase of the combined effect of power and traverse speed results in larger depths. Lallemand (2000) studied the influence of different gas inlet angles on groove depth and width. He concluded that both depth and width are dependent on the material itself (heat conduction properties) as well as on different gas inlet angles. The same results have been found by $\mathrm{Li}$ et al. (2005) who studied the melt removal rate for three different materials and found that the highest heat conductor produces shallow and wide channels. Mai and Lin (2003) studied the influence of a centred gas pressure in combination with an off-axis jet at various angles on the depth. They found that at different 
angles, in combination with different gas pressures, the melt removal rate varied; as well as the appearance of dross on the sides of the groove. O'Neill et al. (2001) showed that the groove depth is dependent on power and independent of assist gas; the assist gas is only required to remove the material out of the groove. Recent research has been carried out by Stournaras et al. (2009). Their theoretical model for a pulsed laser predicted that the groove depth is dependent on the traverse speed as well as the laser power.

A large proportion of the research conducted on laser grooving so far has been focused on theoretical predictions with relatively few examples of practical research. Few researchers (Mai and Lin, 2006) have addressed the relationship between melt removal and melt displacement for laser grooving which is of particular interest for 3D micromachining processes that demand precision and accuracy for manufactured parts (Meijer et al., 2002). Spatter formation is a common problem in laser micromachining and originates from ejected material that is not completely removed from the channel, drilled hole (Low et al., 2003) or cut kerf (Riviero et al., 2008). A solution to prevent spatter formation in micromachining is the use of pulsed lasers which allow high peak power densities that lead to vaporisation of the material (Bandyopadhyay et al., 2002). Jha (2007) generated micro channels in aluminium in the micrometre range and found that reacting forces with the material due to energy densities might lead to the deformation of the channels. Kumar and Gupta (2010) stated that higher fluencies lead to the ejection of melt and vaporisation in laser drilling. For cleaner edges i.e. less spatter, lower fluencies had to be used. 
This paper investigates the use of a fiber laser for the production of micro channels in ultrasonically consolidated samples. Ultrasonic Consolidation (UC) is an additive manufacturing method based on the ultrasonic welding of a sequence of metal foils. The process is suited to producing complex 3D metal parts by combining ultrasonic metal welding and Computer Numerical Control (CNC) milling techniques (White, 2003). A schematic overview of the process is given in Figure 1(a).
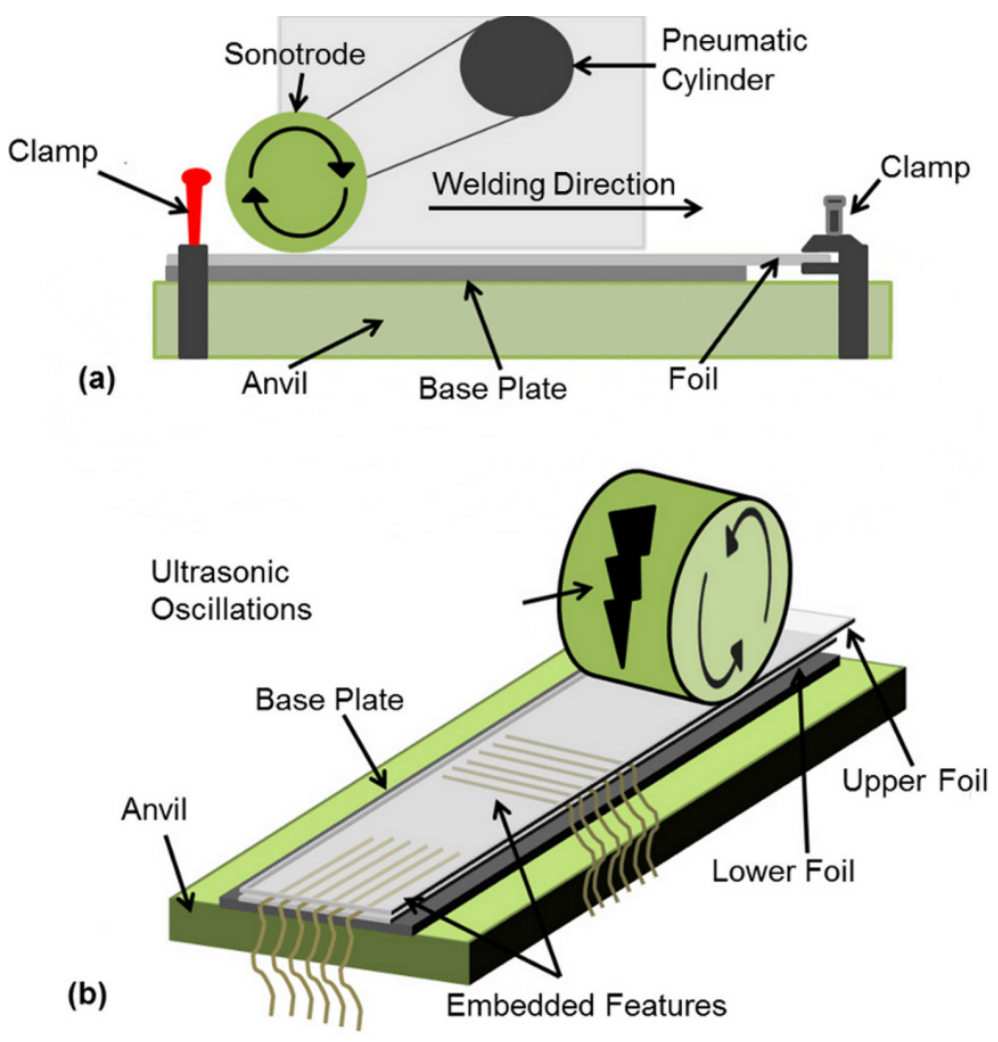

Fig. 1 Schematic overview of the Ultrasonic Consolidation process a) front view and b) embedding features

Two key aspects of UC are: Firstly, bond formation is achieved at temperatures lower, (typically $\leqslant 50 \%$ ), than the melting temperature of the foil material (Kong, 2004). Secondly, highly localised plastic flow occurs during ultrasonic 
excitation of the metal foil (Langenecker, 1966). These two aspects (solid state low temperature processing and high plastic flow) allow certain components, prone to damage or sensitive to high temperatures, to be embedded via UC (Cheng et al., 2007) as schematically displayed in Fig. 1(b). In particular, the integration of different types of active and passive fibres seems to be a promising application for UC to produce adaptive composites (Kong and Soar, 2005). In order to truly exploit the potential of UC as an application for adaptive composite manufacturing high volume fractions of fibres must be realised for effective active structure control and monitoring. Latterly, Friel (Friel and Harris, 2010) embedded a total of ten NiTi Shape Memory Alloy fibres within an Al $3003(\mathrm{O})$ foil matrix and discussed that fibres have a weakening effect on foil to foil bond formation during UC. In addition, UC sonotrode oscillation amplitudes are necessary to induce sufficient material flow in the matrix and void closure (Yang et al., 2009) around a higher number of fibres. By increasing the UC sonotrode oscillation amplitude the fibres to be embedded can be adversely affected. To reduce the required amplitude, and thus the necessary matrix plastic flow, Kong and Soar (2005) used a hard fibre to form a groove in the matrix material prior to fibre placement and subsequent UC.

In this paper the authors present an approach to produce channels in UC samples with the use of a fiber laser. A schematic overview of the process can be seen in Fig. 2. UC samples would be irradiated by the fibre laser to create a channel (Fig. 2 (a)). By manipulating the resulting spatter/melt formation in combination with the assist gas the spatter/melt on either side of the channel 
boundaries could be distributed (Fig 2 b) and c)), which would in turn reduce the required level of plastic flow during future fibre embedding (Fig. 2 d)).

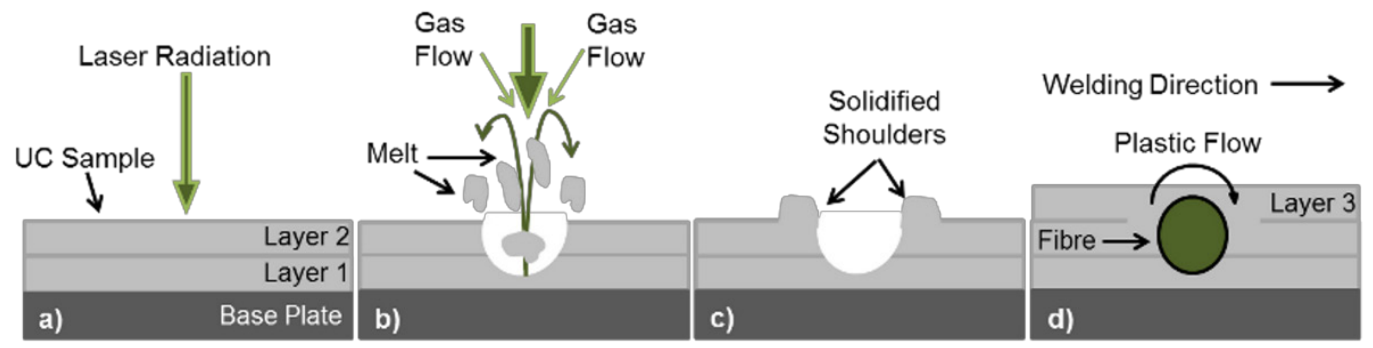

Fig. 2 Overview of intended approach to create channels by manipulation of laser/material and assist gas interaction

The main aim of the channel/shoulder generation for future fibre integration was as follows: accurate channel geometries would likely enhance accurate high volume fibre placement and reduce fibre distortion, while applying oscillations and pressure during UC. Additionally, it was proposed that the shoulders would provide additional material which would facilitate plastic flow around embedded fibres during UC.

\section{Methodology}

All of the laser experiments were conducted on samples consisting of aluminium alloy $3003-\mathrm{H} 18$. The material was chosen due to its use in earlier UC studies on fibre embedding (Yang et al., 2010) which allows comparison of the effects of laser processing. The alloy was supplied as a foil by United Aluminum, USA (24 mm wide and $100 \mu \mathrm{m}$ thick) and had a nominal composition of: Al 97 wt \%, Mn 1.5 wt \%, Si 0.6 wt \%, Fe 0.7 wt \%, Cu 0.2 wt \%. 


\subsection{UC Sample Manufacture}

Prior to the laser processing, samples were manufactured using Loughborough University's Alpha 2 UC machine. The machine was supplied by Solidica INC., USA and had been used in several previous UC studies (Kong, 2004; Friel et al. 2010). Variable process parameters of the UC machine are: sonotrode oscillation amplitude $(\mu \mathrm{m})$, welding speed $(\mathrm{mm} / \mathrm{s})$ and welding force $(\mathrm{N})$. These parameters were maintained at constant values of $40 \mathrm{~mm} / \mathrm{s}$ for welding speed, $1400 \mathrm{~N}$ for welding force and $20 \mu \mathrm{m}$ for the sonotrode oscillation amplitude. The manufacturing procedure for the samples was consistent with previously published work (Masurtschak, 2011).

\subsection{Laser Processing}

The laser used in this study was a Trumpf TruFiber $300 \mathrm{~W}$ laser with a wavelength of $1.085 \mu \mathrm{m}$. A fiber laser was selected at this stage of investigation due to beam quality factors of $\mathrm{M}^{2} \leqslant 1.2$ which allowed focusing to a small spot size, hence a high power density and a Gaussian distribution of the beam (Han and Liou, 2004). It was predicted that higher beam qualities exhibiting different intensity distribution profiles would lower the possibility to manufacture semicircular shaped channels, which would likely enhance secure positioning of circular fibres. Additionally, it was proposed that higher order modes would modify the heat input into the material, which could possibly make the flow pattern of the melted material more difficult to control (Han and Liou, 2004).

All experiments on the Trumpf TruFiber $300 \mathrm{~W}$ were carried out in continuous wave mode with a calculated spot size of $13.8 \mu \mathrm{m}$. The irradiance of the 
incident beam corresponded to $1.48 \times 10^{8} \mathrm{~W} / \mathrm{cm}^{2}$ for $200 \mathrm{~W}$ and $2.23 \times 10^{8} \mathrm{~W} / \mathrm{cm}^{2}$ for $300 \mathrm{~W}$. The assist gas was supplied through a conical cutting nozzle. The gas utilised throughout the experiments was air. A schematic representation of the set-up can be seen in Fig. 3 .

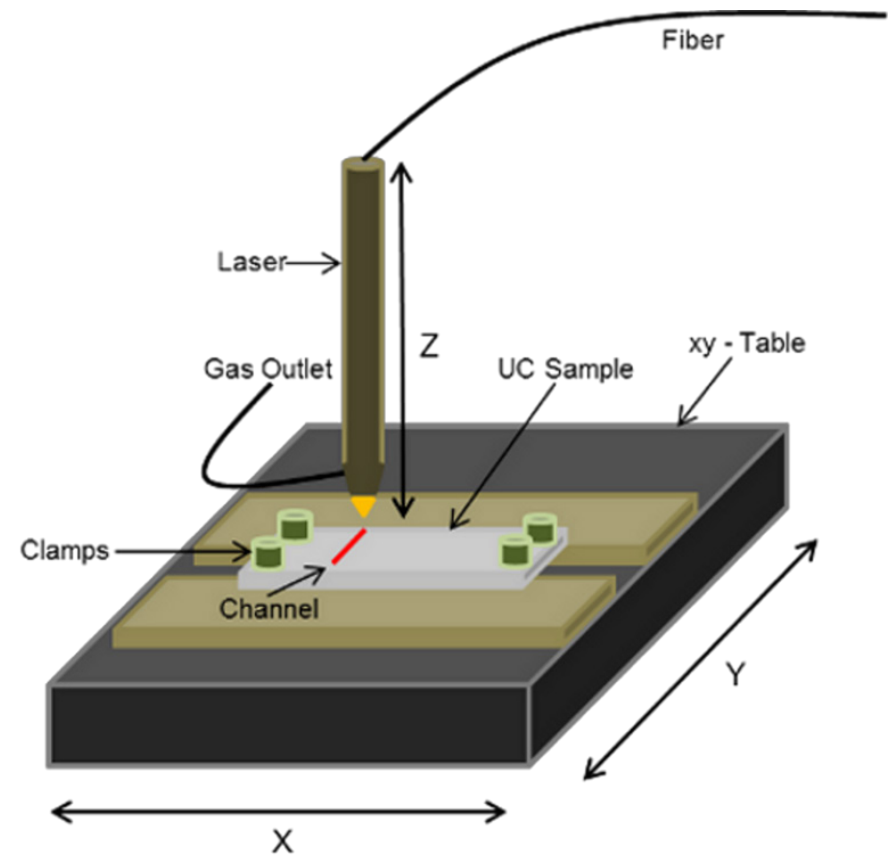

Fig. 3 Schematic set-up for samples processed with Trumpf TruFiber 300W laser

The UC sample was fixed on a CNC working table which could be operated in the $\mathrm{X}$ and $\mathrm{Y}$ direction. Experiments were carried out by varying the traverse speed $(\mathrm{mm} / \mathrm{s})$, laser power $(\mathrm{W})$ and assist gas pressure (bar). The scanned laser channels had a length of $15 \mathrm{~mm}$. Table 1 lists the parameters variations that were used. 
Table 1 Varied parameters for a single pass on Trumpf TruFiber $300 \mathrm{~W}$

\begin{tabular}{|c|c|c|}
\hline $\begin{array}{c}\text { Gas } \\
\text { Pressure } \\
{[\text { Bar] }}\end{array}$ & $\begin{array}{c}\text { Power } \\
{[W]}\end{array}$ & $\begin{array}{c}\text { Traverse Speed } \\
{[\mathrm{mm} / \mathrm{s}]}\end{array}$ \\
\hline 2 & $100 ; 200$ & $100 ; 300 ; 500$ \\
\hline 4 & $100 ; 200$ & $100 ; 300 ; 500$ \\
\hline 6 & $100 ; 200$ & $100 ; 300 ; 500$ \\
\hline 8 & $100 ; 200$ & $100 ; 300 ; 500$ \\
\hline
\end{tabular}

The beam was focused above the surface of the aluminium material which is consistent with laser cutting operations (Wandera, 2009). The distance between the sample and the nozzle was kept constant at $0.4 \mathrm{~mm}$.

Experiments were conducted to analyse the effect of multiple laser passes on channel geometry. These experiments were conducted by radiating the material surface three or five times. Results from single scans were taken into account and the parameters for multiple laser scans were refined accordingly. Table 2 details the range of varied parameters that were used. The gas pressure was varied between 4 bar and 8 bar in order to determine the gas flow effect on displacing the melt from the channel. The power was varied between $150 \mathrm{~W}$ to $280 \mathrm{~W}$, in order to determine the effect of power on channel creation. The traverse speeds were $100 \mathrm{~mm} / \mathrm{s}, 200 \mathrm{~mm} / \mathrm{s}$ and $500 \mathrm{~mm} / \mathrm{s}$. 
Table 2 Varied parameters for multiple passes on Trumpf TruFiber $300 \mathrm{~W}$

\begin{tabular}{|c|c|c|c|}
\hline Passes & $\begin{array}{c}\text { Gas } \\
\text { Pressure } \\
\text { [bar] } \\
\end{array}$ & $\begin{array}{c}\text { Traverse Speed } \\
{[\mathrm{mm} / \mathrm{s}]}\end{array}$ & $\begin{array}{c}\text { Power } \\
{[W]}\end{array}$ \\
\hline \multirow{6}{*}{3} & \multirow{3}{*}{4} & 100 & $150 ; 200 ; 250 ; 280$ \\
\hline & & 200 & $150 ; 200 ; 250 ; 280$ \\
\hline & & 500 & $150 ; 200 ; 250 ; 280$ \\
\hline & \multirow{3}{*}{8} & 100 & $150 ; 200 ; 250 ; 280$ \\
\hline & & 200 & $150 ; 200 ; 250 ; 280$ \\
\hline & & 500 & $150 ; 200 ; 250 ; 280$ \\
\hline \multirow{6}{*}{5} & \multirow{3}{*}{4} & 100 & $150 ; 200 ; 250 ; 280$ \\
\hline & & 200 & $150 ; 200 ; 250 ; 280$ \\
\hline & & 500 & $150 ; 200 ; 250 ; 280$ \\
\hline & \multirow{3}{*}{8} & 100 & $150 ; 200 ; 250 ; 280$ \\
\hline & & 200 & $150 ; 200 ; 250 ; 280$ \\
\hline & & 500 & $150 ; 200 ; 250 ; 280$ \\
\hline
\end{tabular}

In order to determine the possibility of processing repeatable and consistent channels to study the applicability of embedding higher volume fractions of fibres in further work, the following experiment was performed: Samples with 8 and 24 channels were generated by multiple scans. Due to a sample width of $24 \mathrm{~mm}, 24$ channels were chosen to be generated perpendicular to the welding direction in order to avoid interference of the channels/shoulders - the distance between the channels was set to $800 \mu \mathrm{m}$ measured from the beginning of one channel to the beginning of the next channel.

\subsection{Channel Characterisation}

For examination of the 3D profile of the channels a Keyence digital microscope (VHX - 600 Series with a VH-Z100R lens) was employed. A magnification of $x 300$ was used to observe the channel geometry. This type of observation allowed an inspection of channel depth and shoulder height. The desired channel geometry was determined as a result of the dimensions of the fibres to 
be embedded in future work. The desired parameters for channel geometry were: a width of $120 \mu \mathrm{m}-150 \mu \mathrm{m}$, a depth of $50 \mu \mathrm{m}$ to $80 \mu \mathrm{m}$ and a shoulder height of $50 \mu \mathrm{m}$ to $80 \mu \mathrm{m}$.

The channels were further examined with an Olympus BX 60M optical microscope equipped with a MicroPublisher 3.3.RTV digital camera. This allowed further characterisation of the geometry of the channels and of the shoulder. The samples were cross-sectioned perpendicular to the channel direction and mounted into Buehler Konductomet II. The surface was ground to a surface finish of $1 \mu \mathrm{m} \mathrm{R}_{\mathrm{a}}$ and then polished with colloidal silica to a surface finish of $0.1 \mu \mathrm{m} R_{a}$. The samples were then etched with Keller's reagent for 30 seconds. A magnification of $\times 10$ with an additional $\times 10$ magnification from the eye-pieces was used. Measurements were taken from the width and depth of the channel, and the height of the shoulder feature. These measurements were then compared between each sample to determine the possible influences of the laser parameters.

Analysis of the channel geometries consistency and repeatability, for 8 and 24 channels, was conducted by scanning the surface with an inductive gauge. A Taylor Hobson Talysurf CLI 2000 inductive gauge was programmed to scan the channel at four points equally distributed over the whole length in order to obtain the height of the shoulder and the depth of the channel. Determination of the consistency and repeatability of the desired channel geometry over the length of the channel furthered the understanding as to the applicability of laser channels to potentially securely embed and position fibres within a UC metal matrix composite. 


\section{Results and Discussion}

\subsection{Single Laser Scan}

Laser processing of the material in a single scan resulted in two different effects on the surface of the sample - both of them insufficient for channel creation. The two typical effects to the surface of a UC sample are shown in Fig. 4 (a) and (b). Fig. 4 (c) shows the microscopic view of Fig 4. (a).

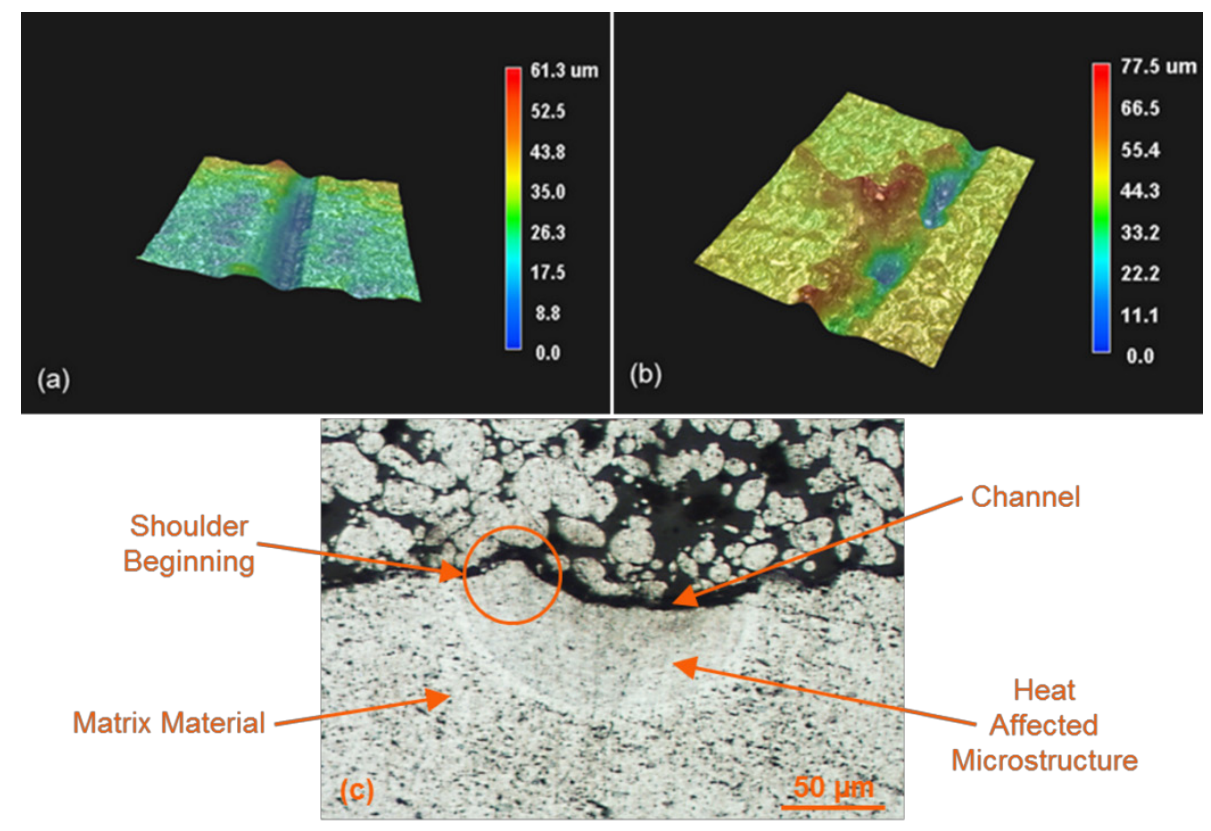

Fig. 4 Single scan channel formation (a) insufficient depth and (b) partially melted channel (c) microscopic view of channel with a magnification of $\times 100$

Fig. 4 (a) demonstrates that a channel path was created and indications of a shoulder feature on one side of the channel path could be seen. The analysed samples exhibited a penetration depth between $10 \mu \mathrm{m}$ to $20 \mu \mathrm{m}$. The second effect is illustrated in Fig. 4 (b): some of the sample materials were partially deepened and an uneven surface occurred within the channel. Although, a 
shoulder feature was identified, the melted material was inconsistently placed on one side of the channel.

A reason for the unstable penetration, demonstrated in Fig. 4(b), may have been the inherent surface roughness of the samples. The surface roughness of the foil material is purposefully induced while applying oscillations to the material as a natural part of the UC process (Li and Soar, 2009). In Fig. 5 the typical surface topology of a sample produced by UC is demonstrated. The surface roughness varied constantly over the sample area. The arithmetic mean deviation value of the surface was stated to be $S_{a}=4.97 \mu \mathrm{m}$ (Edmonds and Harris, 2011). As a result of this, the reflection of the laser beam would vary with the surface geometry while radiating. Therefore the inconsistent penetration depth produced by the laser may have been due to the surface roughness.

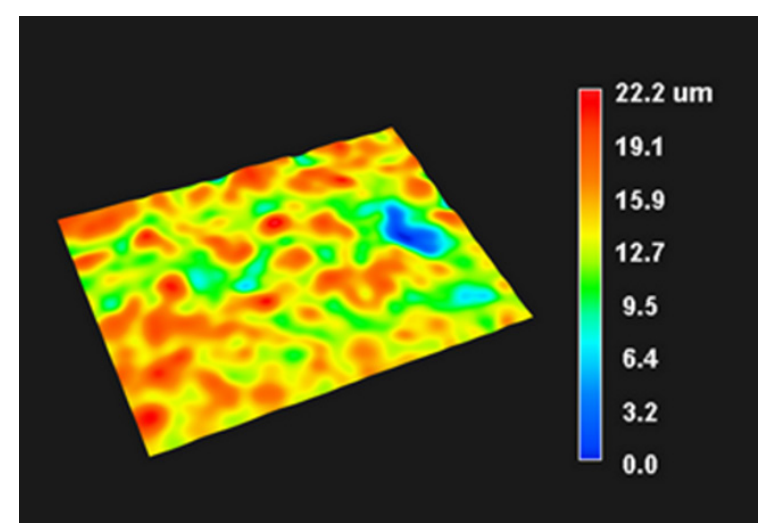

Fig. 5 Example surface topology of a UC processed sample prior to laser processing

As a result of the varying surface topology a variable channel depth has been accomplished. This might have been an indication that in the deeper areas melt was generated and placed on the sides of the channel. However, the partly 
deepening of the channel indicated that instead of a stable melt pool over the whole length of the channel, small single melt pools might have formed which were likely to have been caused by insufficient heat input to the material.

Another factor that may have lessened the penetration depth is the significant presence of aluminium oxide $\left(\mathrm{Al}_{2} \mathrm{O}_{3}\right)$ which is likely formed when the aluminium is exposed to air. The oxide layer grows over time on the rough aluminium surface and has a high melting temperature $(2320 \mathrm{~K})$, whereas the melting point of $\mathrm{Al} 3003$ is around $930 \mathrm{~K}$ (Mondolfo, 1976). Therefore, it might be possible that the melting temperature of the oxide layer, due to insufficient input energy, was not reached and subsequently presented an obstacle where the beam was reflected too much. Due to the roughness of the samples, the oxidised surface covers a larger area as opposed to the oxidised flat areas for flat samples.

The depth and consistency of the single pass laser channels were neither deep nor consistent enough for their intended function (subsequent fibre placement). However, it was evident from the single laser scan experiments that channels and shoulders were produced.

\subsection{Multiple Laser Scans}

In the methodology section it was described that tests were carried out at traverse speeds of 100, 200 and $500 \mathrm{~mm} / \mathrm{min}$. However, the laser interaction obtained at a travel speed of $500 \mathrm{~mm} / \mathrm{min}$ for samples was shown to be insufficient for channel creation. A possible reason for less penetration depth might be that the travel speed was too high to achieve sufficient melting. For this reason the following results are displayed for $100 \mathrm{~mm} / \mathrm{min}$ and $200 \mathrm{~mm} / \mathrm{min}$. 
Fig. 6 (a) and (b) displays the influences of laser power, travel speed and assist gas on the width and the depth of the channel. The channel was radiated three times.
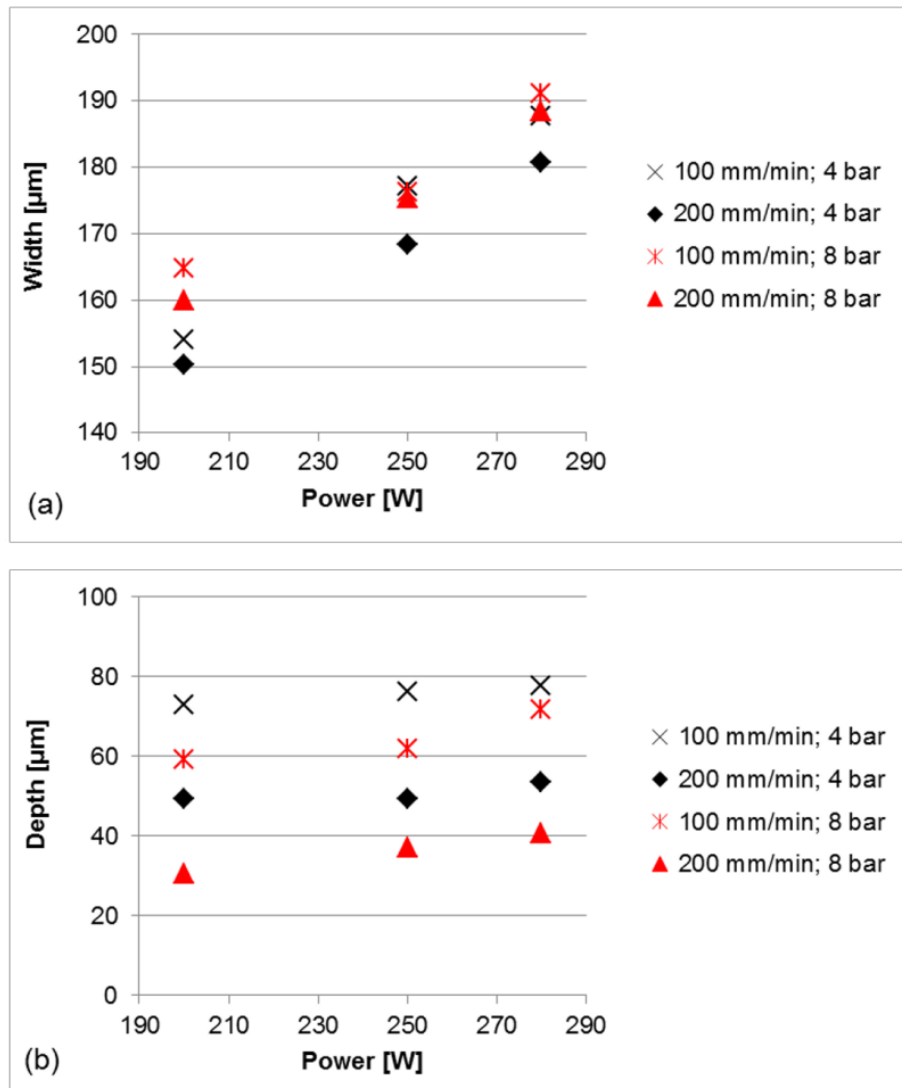

Fig. 6 Influence of power, traverse speed and gas flow on the width (a) and the depth (b) of three times radiated channels

Fig. 6 (a) shows that the channel width increased with higher laser power, which was likely due to the greater power density applied to the work piece. The results revealed that the channel width was in the range of $150 \mu \mathrm{m}$ to $190 \mu \mathrm{m}$ and therefore wider than desired. A slower travel speed and lower assist gas pressure resulted in greater channel width for all experiments at $200 \mathrm{~W}$. The depth in Fig. 6 (b) increased $10 \mu \mathrm{m}$ for higher powers and the traverse speed had a noticeable effect on the penetration depth. Higher traverse speeds 
led to less penetration than slower traverse speeds (for the range of $100 \mathrm{~mm} / \mathrm{min}$ and $200 \mathrm{~mm} / \mathrm{min}$ a decrease of $10 \mu \mathrm{m}$ to $20 \mu \mathrm{m}$ was found). This is in agreement with work by Katayama (2009). Further analysis of the penetration depth also revealed that the assist gas had only a minimal effect on the penetration. The difference between 4 bar and 8 bar was approximately $10 \mu \mathrm{m}$ which indicated that the main process parameters which influenced the depth of the channel were lower laser power density and the interaction time between the laser and material.

Results of the five laser pass experiments are shown in Fig. 7 for the width (a) and depth (b) of the channels.
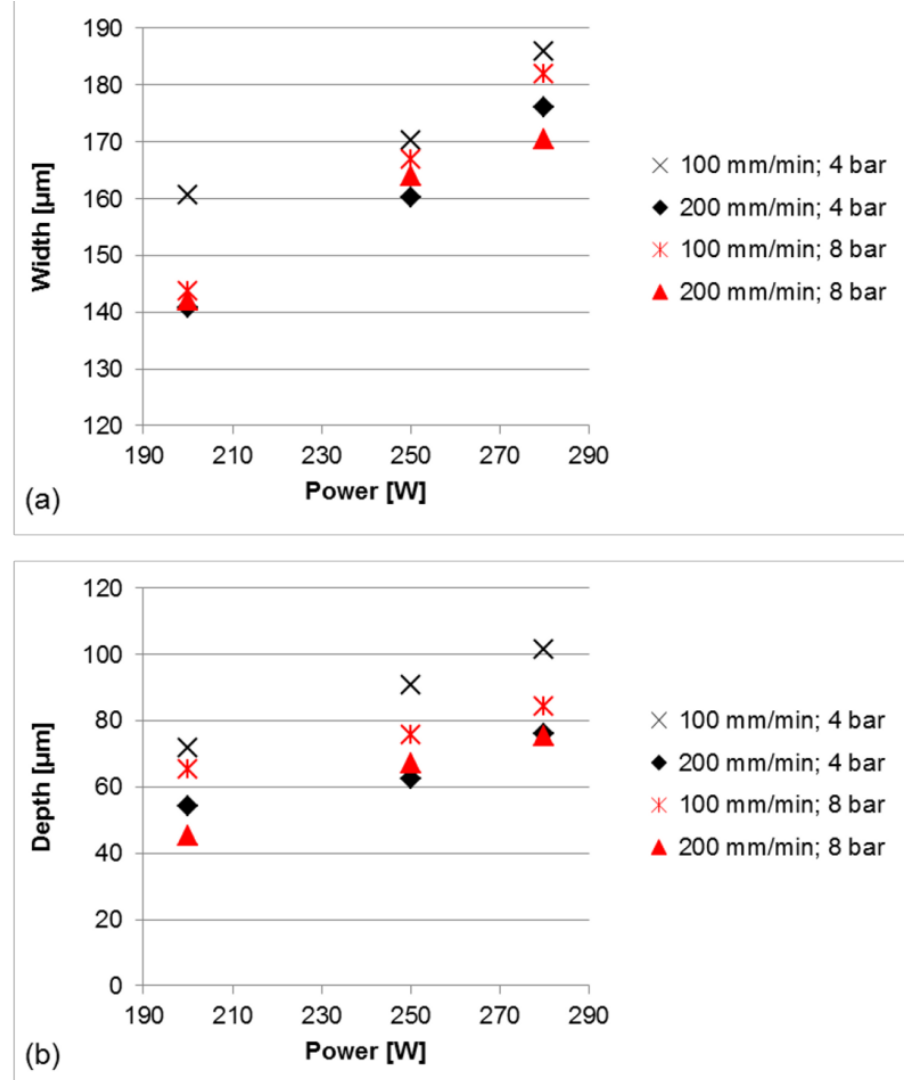

Fig. 7 Influence of power, traverse speed and gas flow on the width (a) and the depth (b) of five times irradiated channels 
An increase in laser power resulted in a larger channel width $(140 \mu \mathrm{m}$ to 190 $\mu \mathrm{m})$. Both three and five passes exhibited a linear behaviour between power density and the width of the channel which was in agreement with previous work (Chryssolouris, 1988).

Applying a slower processing speed of $100 \mathrm{~mm} / \mathrm{min}$ to the work piece resulted in wider channels than when using a processing speed of $200 \mathrm{~mm} / \mathrm{min}$, (this result was also obtained for three passes). This was another indication that a longer interaction time between the laser and $\mathrm{Al} 3003-\mathrm{H} 18$ surface accounted for a wider channel. A decrease in traverse speed resulted in a longer interaction time between the laser and metal material, thus resulting in a larger melt area, which was subsequently expunged via the assist gas and therefore this created a wider channel.

It was interesting to note that an influence of the assist gas on channel width was not apparent for five passes. Since this behaviour correlated with three passes it could be interpreted that the assist gas may not be a major driving force for channel width. Furthermore, a comparison of the channel width for three and for five passes revealed that the channel width varied in the same range of $140 \mu \mathrm{m}$ to $190 \mu \mathrm{m}$. Therefore it was suggested that the laser spot size, interaction time and laser power may have been the main contributing factors in determining the final channel width.

The channel depth of five pass samples increased with higher power as shown in Fig. 7 (b). In comparison with three passes, Fig. 6 (b), this increase was greater and increased further with a slower traverse speed. A linear relationship 
between the power and depth could be depicted. As with the 3 pass experiments it was noted that a slower traverse speed accomplished a deeper penetration into the material. The 5 pass experiments resulted in deeper channels than for the 3 pass experiments which suggested that the increased laser/material interaction time had an effect on channel deepening. Similar findings have been discovered in previous work (Mai and Lin, 2006).

Paleocrassas and Tu (2010) stated that in low-speed keyhole welding an increase in the reflectivity of the beam is noted as a result of a shallow keyhole and its inability to absorb the entire beam. A possible explanation could be that higher processing rates i.e. more scans led to a larger and deeper melt pool in which the beam was trapped and as result the channel became deeper. This would be in accordance to one and three scans compared to five scans; as the melt pool became larger, with more passes, the beam may have been more likely to be absorbed in the melt and as a result deepen the channel.

The influence of assist gas on the channel depth for five passes did not appear to be as pronounced as for other processing parameters. Three passes showed the depth to decrease by $10 \mu \mathrm{m}$ between 4 bar and 8 bar respectively. It was concluded that a higher assist gas pressure caused the melt to cool down faster which prevented the channel from deepening.

Fig. 8 illustrates the influence of power, traverse speed and assist gas on the shoulder creation for three passes (a) and five passes (b). 

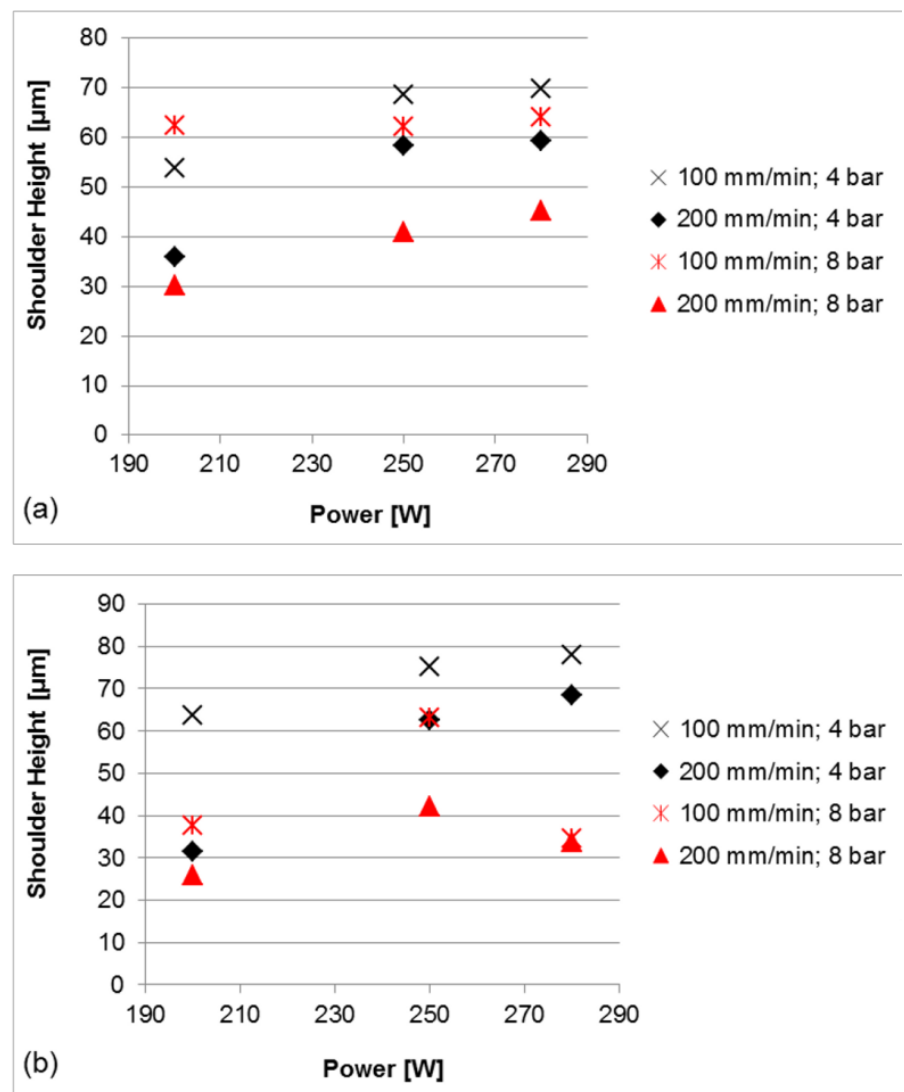

Fig. 8 Influence of power, traverse speed and gas flow on the height of the shoulder established next to the channel (a) three passes and (b) five passes

For three passes it was noted that the shoulder height for slower processing speeds was higher than for higher processing speeds. The height varied between $55 \mu \mathrm{m}$ and $70 \mu \mathrm{m}$ for both assist gas pressures. The same influence was noted for five passes with a range of $40 \mu \mathrm{m}$ to $80 \mu \mathrm{m}$. Comparison of the shoulder height and the channel depth demonstrated that there was a correlation between the two. A trend of an increasing shoulder height by increasing the laser power was obtained between $200 \mathrm{~W}$ and $250 \mathrm{~W}$ for 4 bar. For 8 bar, the same trend was noted for five passes but not for three passes, for which the shoulder height stayed similar for all three powers. The shoulder heights varied in the range of $10 \mu \mathrm{m}$ between the highest shoulder for three 
passes $(70 \mu \mathrm{m})$ and the highest shoulder for five passes $(80 \mu \mathrm{m})$ as can be seen in Fig. 8 (a) and (b). This suggested that the majority of the melted material from the channel was deposited on the material surface at the side of the channel and therefore used for shoulder creation. This suggested that the material inside of the channel was melted by the laser interaction and not vaporised.

The observed difference of shoulder formation from applying two different assist gas pressures was less than for the other processing parameters. A lower gas pressure of 4 bar applied to the work piece resulted in a higher shoulder when compared to samples manufactured with 8 bar. A possible reason for a lower gas pressure responsible for a higher shoulder may have been due to a slower cooling rate of the melt pool. Though the gas pressure did not appear to have as large an effect on channel depth and shoulder height as the other varied parameters it was thought that it was the mechanism by which the melt pool was displaced from the channel onto the surface of the material. This is in accordance with previous work (Wandera, 2010) that found that the assist gas pressure was a main contributor to a high melt removal rate in the kerf, during laser cutting.

\subsection{D analysis of the shoulder feature}

Fig. 9 displays four channels for 3 and 5 passes at assist gas pressures of 4 bar and 8 bar taken with the Keyence VHX 600 Series. To facilitate the comparison all channels displayed were processed with the same laser power and traverse speed. 

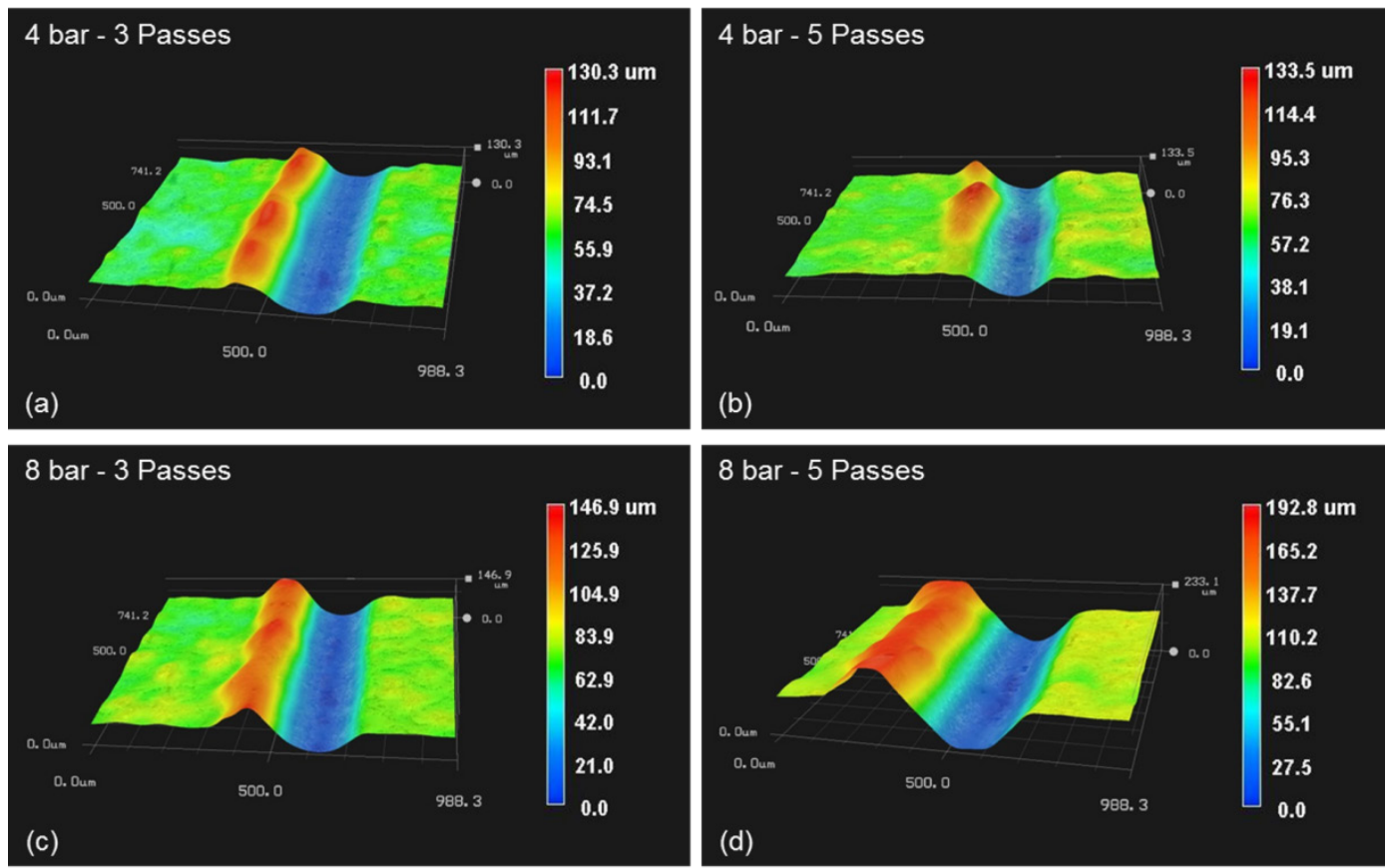

Fig. 9 Comparison influence of different gas pressures and passes (sample processed with a speed of $200 \mathrm{~mm} / \mathrm{min}$ and power of $280 \mathrm{~W}$ )

It was observed that the channels exhibited a circular shaped channel profile which was considered an important factor for embedding circular fibres. The inside of the channels appeared as a smooth area without peaks or inconsistent channel depths. The shoulder feature was not found on both sides of the channel but instead occurred on one side of the channel. This was identified for every channel produced. It was also noted that the shoulder always appeared on the left side of the channel (i.e. to the left side of the laser when standing in front of it). The melt was built-up in accurate consistent paths to the side of the channel and additional material spatter was not apparent.

It was unlikely that the beam would have caused this phenomenon as the channel showed a Gaussian-shaped outline and a Primes MicroSpot Monitor was used to align the beam. This meant that the beam was aligned to the 
middle of the nozzle and was not clipping on the sides of the nozzle which would have caused a different power density distribution. However, two possible influences which may have caused the shoulder to build up one-sided are: a non-uniform heating of the melt-front, which was reported and developed into a 3D model by Chan et al. (1988), and/or a non-uniform distribution of gas.

The non-uniform heating of the melt-front in the channel may be explained by the Gaussian distribution causing a higher heat input to the centre of the molten pool than at the channel boundaries. As a consequence a decrease in temperature towards the edges of the channel could have resulted in an increase in surface tension towards the channel boundaries. Due to the surface tension and wetting characteristics, the melt could have been pulled to either one side of the channel or the other.

The non-uniform distribution of gas could possibly be caused by air not flowing coaxially from the nozzle but instead flowing off-axially. It was possible that the air stream may have approached the material with an angle of less than $90^{\circ}$ from the right side which in turn forced the melt to be built-up on the left side of the channel. Another possible explanation for the shoulder formation was based on the approach for side gas explanation stated by Kamimuki et al. (2002). The off-axis gas flow impinges on the channel wall and is converted back in the direction were it came from. This would have resulted in the build-up of the material under the gas inlet side. A substantiation for the shoulder formation due to a non-uniform gas distribution was established when test results performed at Loughborough University using a different laser setup demonstrated the same phenomena; suggesting it was not limited to the 
specific equipment used in this study. Further investigation on the assist gas flow was carried out by monitoring the impingement of the gas on a soft, rubberlike material which deformed upon application of the assist gas. The results further demonstrated that the material would rise at the left side of the laser spot, whereas the right side of the laser spot was not affected by the assist gas. However, as the shoulder was noted to appear on the same side of the channel each time, an additional experiment was carried out; in order to determine if the shoulder would be alternating between the right and left side of the channel, a square was radiated into a UC sample. The results showed that the shoulder position did not alternate between the channel sides, which supported the nonuniform heating of the melt pool theory. For this reason it remained unclear which of the two possible influences may have caused the single-sided shoulder formation. Fig. 10 displays the microscopic image of a channel, and the shoulder built-up on the edge of the channel manufactured with the same parameters as Fig. 9 (d). In addition to creating the channel and shoulder, the laser affected the microstructure and the interface between the two foils.

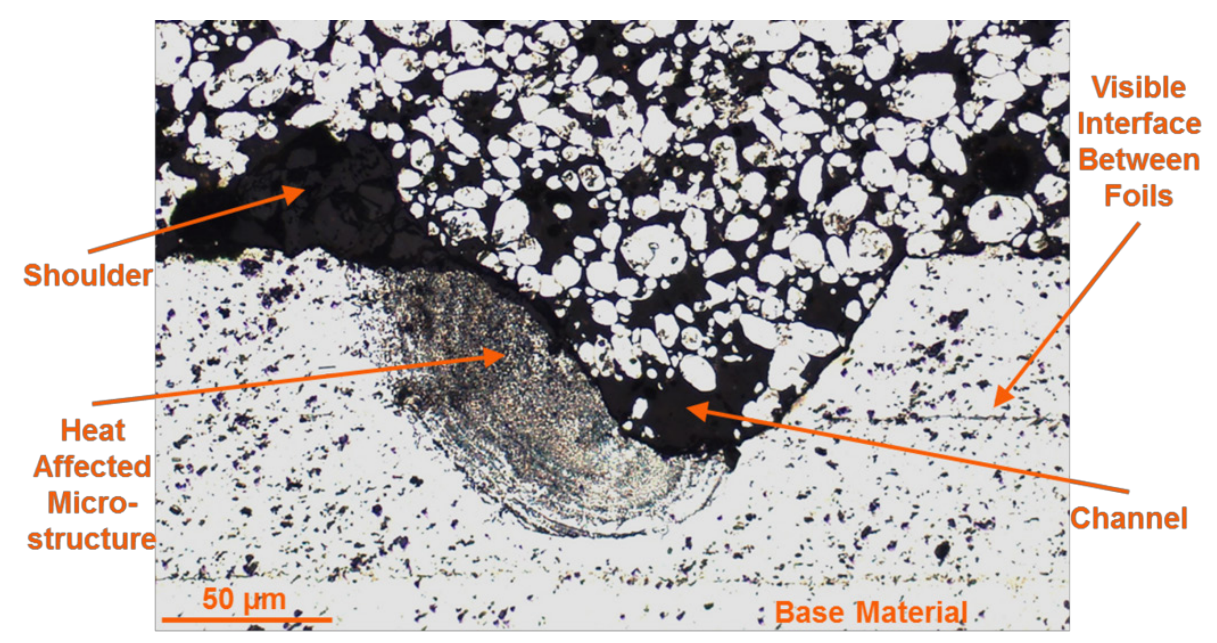

Fig. 10 Microscopic image of a channel/shoulder (5 passes, $8 \mathrm{bar}, 200 \mathrm{~mm} / \mathrm{min}$ and $280 \mathrm{~W}$ ) 
As a one-sided shoulder differed from the expected two shoulders shown in Fig. 2 (c), it was necessary to discuss the possible effect of a one-sided shoulder on future fibre embedding and ultrasonic consolidation. With regards to placement and positioning of fibres, the shoulder was expected to not interfere as the channel was used to securely position the fibres. The shoulder on one side may have an effect on the fibre embedment and the plastic flow during UC. Research on the fibre embedment and the plastic flow behaviour is currently carried out.

\subsection{Repeatability and Consistency of Channel Processing}

Samples were successfully produced with 8 and 24 channels. Fig. 10 shows the surface profile of a sample with 24 channels which was to be used for further processing and fibre embedding in future studies. Each of the 24 channels was radiated five times in order to achieve a sufficient channel depth. Fig. 10 (a) shows the surface area that was scanned with an inductive gauge. The five scanned lines were put together to create an overview of the whole channel. A top view of the 24 channels is provided in Fig. 10 (b). 
(a)

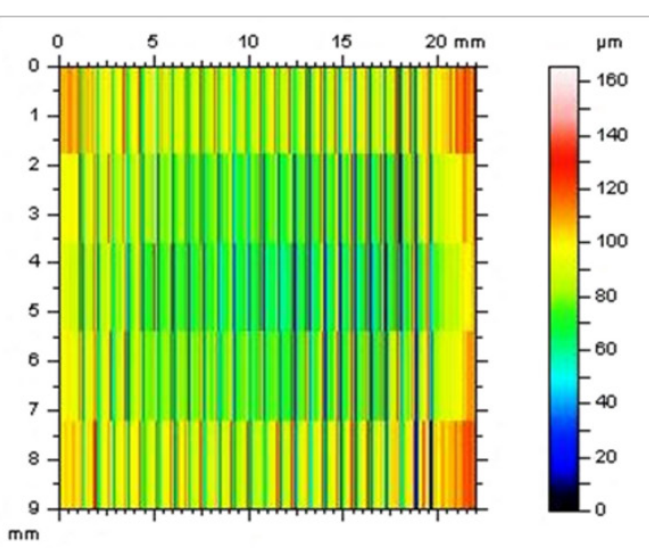

(b)

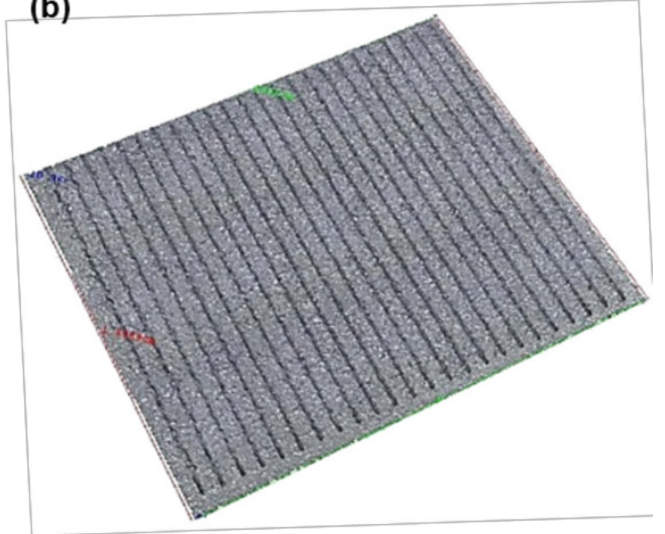

Fig. 11 Surface profile of 24 channels a) 2D contour map and b) 3D top view of channels with a distance of $800 \mu \mathrm{m}$ between the channels

To allow a comparison of the laser effect on the samples, Fig. 11 (a) and (b) display the original surface profile before laser processing and the surface profile after laser treatment with 24 channels.

(a)

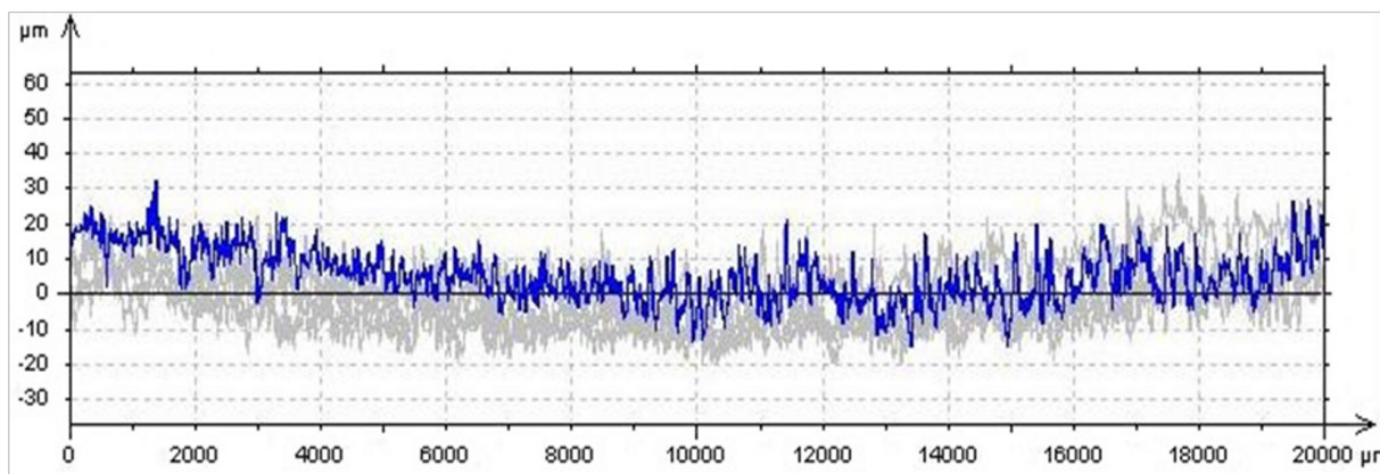

(b)

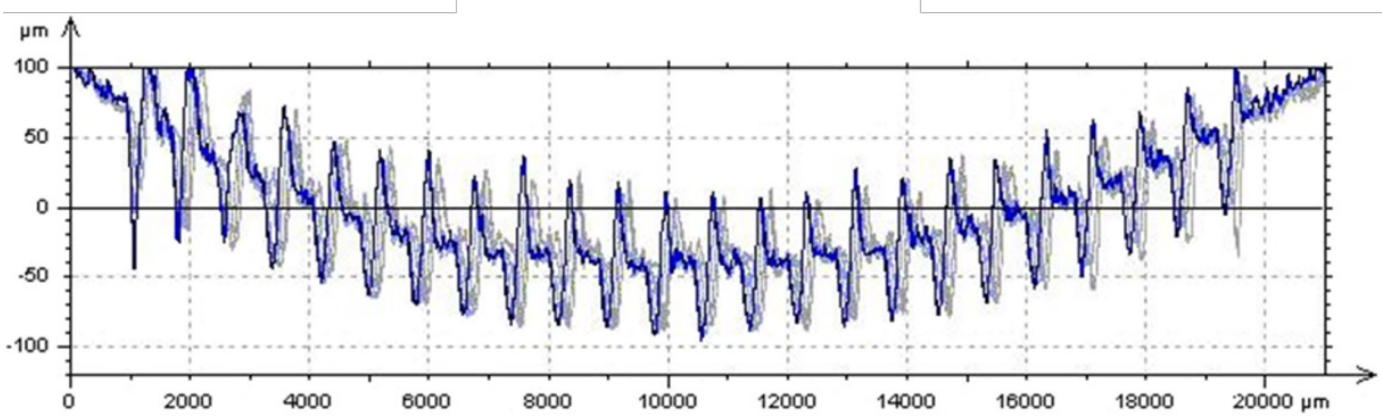

Fig. 12 2D Profile of a UC sample (a) original profile before laser processing and (b) profile after laser processing showing 24 channels 
The distance between the channels was $800 \mu \mathrm{m}$ and consistent repeatability by the laser was displayed as can be seen in Fig. 11. Due to the laser interaction with the sample, and thus subsequent heat induced distortion, the surface was curved which can be noted in Fig. 11 (b). The depth and width of the channels as well as the shoulder height showed minimal variation across the sample, despite the sample having a rougher surface profile prior to laser processing. This further demonstrated the consistency and stability of the laser-material interaction.

\section{Conclusions and Future Work}

This work demonstrated a unique approach to overcome current issues with fibre embedding in UC. Channels for secure positioning of fibres were successfully produced by utilisation of a fiber laser. Additionally, the laser proved to be a promising tool for accurate, consistent and repeatable production of a high number of channels which may allow the integration of high volume fractions of fibres within UC metal matrix composites as discussed. The research has significantly contributed to the understanding of the influence of laser processing on UC processed AI 3003-H18.

The results have shown that multiple passes of the laser led to a higher removal rate of material. This will be valuable knowledge for future applications as different fibre types have different diameters. Laser power density and traverse speed appear to be the most influential parameters for channel creation.

The produced channels showed a Gaussian profile which would help facilitate the secure positioning and embedding of circular-profile fibres. The width of the 
channels was difficult to control in the desired manner by multiple passes which may have resulted in a movement of fibres within the channels during UC. How the width affects the secure positioning and integration of fibres will be

investigated in future work. A solution to this problem may be found in reducing the spot size. In addition, future research opportunities may involve controlled ablation or vaporisation of material to achieve the required width and depth. Here, pulsed lasers may be of use; however vaporisation and ablation may would result in the loss of material as opposed to the generation of shoulder features.

The influence of the assist gas helped to manipulate the melt, however an unexpected result of one shoulder being created instead of the proposed two shoulders was observed. Further research would be required to investigate the equal dispersion of melt material on both sides of a laser machined channel.

\section{Acknowledgements}

The authors would like to thank the Fraunhofer Institute for Laser Technology (ILT) for their collaboration in this research. The authors also gratefully acknowledge the financial support of the EPSRC/IMCRC through grant number EPSRC IMCRC 275.

\section{References}


Bandyopadhyay, S., Sarin Sundar, J.K., Sundararajan, G., Joshi, S. V., 2002. Geometrical features and metallurgical characteristics of Nd:YAG laser drilled holes in thick IN718 and Ti-6Al-4V sheets. J. Mat. Process. Technol. 127, 83-95.

Chan, I., Mazumder, J., Chen, M. M., 1988. Effect of surface tension gradient driven convection in a laser melt pool: Three-dimensional perturbation model. J. Appl. Phys. 64 (11), 6166-6174.

Cheng, X., Datta, A., Choi, H., Zhang, X., Li, X., 2007. Study on Embedding and Integration of Microsensors Into Metal Structures for Manufacturing Applications. J. Manuf. Sci. Eng. 129 (2), 416-424.

Choi, W.C., Chryssolouris, G., 1995. Analysis of the laser grooving and cutting processes. J. Phys. D: Appl. Phys. 28, 873-878.

Chryssolouris, G., Sheng, P., Choi, W.C., 1988. Investigation of Laser Grooving for Composite Materials. CIRP. Ann. Manf. Technol. 37 (1), 161-164.

Edmonds, H.C., Harris, R.A., 2011. The effect of electro-discharge machined sonotrode topology on interlaminar bonding in ultrasonic consolidation. In: Ounaies, Z., Seelecke, S.S. (Eds.), Proceedings of SPIE 7978, Behavior and Mechanics of Multifunctional Materials and Composites, San Diego, USA, pp. 797814-1-797814-13.

Friel, R. J., Harris, R. A., 2010. A nanometre-scale fibre-to-matrix interface characterization of an ultrasonically consolidated metal matrix composite. Proc. Inst. Mech. Eng. L J. Mater. Des. Appl. 224, 31-40. 
Friel, R. J., Johnson, K. E., Dickens, P. M., Harris, R. A., 2010. The effect of interface topography for Ultrasonic Consolidation of aluminium. Mat. Sci. Eng. A-Struct. 527, 4478-4483.

Han, L., Liou, F.W., 2004. Numerical investigation of the influence of laser beam mode on melt pool. Int. J. Heat. Mass Tran. 4747, 4385-4402.

Jha, H., Kikuchi, T., Sakairi, M., Takahashi, H., 2007. Micro-patterning of an anodic oxide film by anodizing laser-textured aluminium. J. Micromech. Microeng. 17, 1949-1955.

Kamimuki, K., Inoue, T., Yasuda, K., Muro, M., Nakabayashi, T., Matsunawa, A., 2002. Prevention of welding defect by side gas flow and its monitoring method in continuous wave Nd:YAG laser welding. J. Laser Appl. 14 (3), 136-145.

Katayama, S., Nagayama, H., Mizutani, M., Kawahito, Y., 2009. Fibre laser welding of aluminium alloy. Weld. Int. 23 (10), 744-752.

Kong, C.Y., 2004. Ultrasonic consolidation for embedding SMA fibres within aluminium matrices. Compos. Struct. 66 (1-4), 421-427.

Kong, C.Y., Soar, R.C., 2005. Method for embedding optical fibers in an aluminium matrix by ultrasonic consolidation. Appl. Optics. 44 (30), 6325-6333.

Kumar, A., Gupta, M.C., 2010. Laser machining of micro-notches for fatigue life. Opt. Laser Eng. 48, 690-607.

Lallemand, G., Jacrota, G., Cicalab, E., Greveya, D.F., 2000. Grooving by Nd:YAG laser treatment. J. Mat. Process. Technol. 99, 32-37. 
Langenecker, B., 1966. Effects of Ultrasound on Deformation Characteristics of Metals. IEEE Trans. Sonics Ultrason. 13, 1-8.

Li, D., Soar, R., 2009. Influence of sonotrode texture on the performance of an ultrasonic consolidation machine and the interfacial bond strength. J. Mat.

Process. Technol. 209 (4), 1627-1634.

Li, L., Kim, J.H., Shukor, M.H.A, 2005. Grit Blast Assisted Laser

Milling/Grooving of Metallic Alloys. CIRP Ann. Manuf. Technol. 54 (1), 183-186.

Low, D.K.Y., Li, L., Byrd, P.J., 2003. Spatter prevention during the laser drilling of selected aerospace materials. J. Mat. Process. Technol. 139, 71-76.

Mai, C.-C., Lin, J., 2003. Supersonic flow characteristics in laser grooving. Opt. Laser Technol. 35, 597-604.

Mai C.-C., Lin J., 2006. An investigation of the surface contours in laser grooving. Int. J. Adv. Manuf. Technol. 28, 76-81.

Masurtschak, S., Harris, R.A., 2011. Enabling techniques for secure fibre positioning in ultrasonic consolidation for the production of smart material structures. In: Tomizuka, M., Yun, C.-B., Giurgiutiu, V., Lynch, J. P. (Eds.) Proceedings of SPIE. 7981, Sensors and Smart Structures Technologies for Civil, Mechanical, and Aerospace Systems, San Diego, USA, pp. 79816M-179816M-13.

Meijer, J., Du, K., Gillner, A., Hoffmann, D., Kovalenko, V.S., Masuzawa, T., Ostendorf, A., Poprawe, R., Schulz, W., 2002. Laser Machining by short and 
ultrashort pulses, state of the art and new opportunities in the age of the photons. CIRP Ann. Manuf. Technol. 51 (2), 531-550.

Mondolfo L.F., 1976. Aluminium alloys: structure and properties, London, Butterworth.

O'Neill, W., Voglsanger, M., Elboughey, A., Steen, W.M., 2001. On the selective removal of steel by laser-assisted vortex machining. Proc. Instn. Mech. Engrs. Part B. 215, 1051-1064.

Paleocrassas, A.G., Tu, J.F., 2010. Inherent instability investigation for low speed laser welding of aluminium using a single-mode fiber laser. J. Mat. Process. Technol. 210, 1411-1418.

Riviero, A., Quintero, F., Lusquiños, F., Pou, J., Pérez-Amor, M., 2008. Laser cutting of 2024-T3 aeronautic aluminium alloy. J. Laser Appl. 20 (4), 230-235.

Stournaras, A., Salonitis, K., Stavropoulos, P., Chryssolouris, G., 2009. Theoretical and experimental investigation of pulsed laser grooving process. Int. J. Adv. Manuf. Technol. 44, 114-124.

Wandera, C., Salminen, A., Kujanpaa, V., 2009. Inert gas cutting of thicksection stainless steel and medium-section aluminium using a high power fiber laser. J. Laser Appl. 21 (3), 154-161.

Wandera, C., Kujanpaa, V., 2010. Characterization of the melt removal rate in laser cutting of thick-section stainless steel, J. Laser Appl. 22 (2), 62-70. 
White, D. R., 2003. Ultrasonic Consolidation of Aluminium Tooling, Adv. Mat. Process. 161, 64-65.

Yang, Y., Ram, G.D.J., Stucker, B.E., 2009. Bond formation and fiber embedment during ultrasonic consolidation. J. Mat. Process. Technol. 209 (10), 4915-4924.

Yang, Y., Stucker, B.E., Ram, G.D.J., 2010. Mechanical Properties and Microstructures of SiC Fiber-reinforced Metal Matrix Composites Made Using Ultrasonic Consolidation. J. Comp. Mat. 44 (26), 3179-3194.

Fig. 1 Schematic overview of the Ultrasonic Consolidation process a) front view and $b$ ) embedding features

Fig. 2 Overview of intended approach to create channels by manipulation of laser/material and assist gas interaction

Fig. 3 Schematic set-up for samples processed with Trumpf TruFiber 300W laser

Table 1 Varied parameters for a single pass on Trumpf TruFiber $300 \mathrm{~W}$ Table 2 Varied parameters for multiple passes on Trumpf TruFiber 300W Fig. 4 Single scan channel formation (a) insufficient depth and (b) partially melted channel (c) microscopic view of channel with a magnification of $x 100$ Fig. 5 Example surface topology of a UC processed sample prior to laser processing 
Fig. 6 Influence of power, traverse speed and gas flow on the width (a) and the depth (b) of three times radiated channels

Fig. 7 Influence of power, traverse speed and gas flow on the width (a) and the depth (b) of five times irradiated channels

Fig. 8 Influence of power, traverse speed and gas flow on the height of the shoulder established next to the channel (a) three passes and (b) five passes

Fig. 9 Comparison influence of different gas pressures and passes (sample processed with a speed of $200 \mathrm{~mm} / \mathrm{min}$ and power of $280 \mathrm{~W}$ )

Fig. 10 Microscopic image of a channel/shoulder (5 passes, 8 bar, $200 \mathrm{~mm} / \mathrm{min}$ and $280 \mathrm{~W}$ )

Fig. 11 Surface profile of 24 channels a) 2D contour map and b) 3D top view of channels with a distance of $800 \mu \mathrm{m}$ between the channels

Fig. 12 2D Profile of a UC sample (a) original profile before laser processing and (b) profile after laser processing showing 24 channels 